\title{
Kant's Formula of Universal Law
}

\section{Citation}

Korsgaard, Christine M. 1985. Kant's formula of universal law. Pacific Philosophical Quarterly 66, no. 1-2: 24-47.

\section{Published Version}

http://www.wiley.com/bw/journal.asp?ref=0279-0750

\section{Permanent link}

http://nrs.harvard.edu/urn-3:HUL.InstRepos:3201869

\section{Terms of Use}

This article was downloaded from Harvard University's DASH repository, and is made available under the terms and conditions applicable to Other Posted Material, as set forth at http:// nrs.harvard.edu/urn-3:HUL.InstRepos:dash.current.terms-of-use\#LAA

\section{Share Your Story}

The Harvard community has made this article openly available.

Please share how this access benefits you. Submit a story.

Accessibility 


\section{Kant's Formula of Universal Law \\ Christine M. Korsgaard}

Kant's first formulation of the Categorical Imperative, the Formula of Universal

Law, runs:

Act only according to that maxim by which you can at the same time will that it should become a universal law.

$(\mathrm{G} 421 / 39)^{1}$

A few lines later, Kant says that this is equivalent to acting as though your maxim were by your will to become a law of nature, and he uses this latter formulation in his examples of how the imperative is to be applied. Elsewhere, Kant specifies that the test is whether you could will the universalization for a system of nature "of which you yourself were a part" (C2 69/72); and in one place he characterizes the moral agent as asking "what sort of world he would create under the guidance of practical reason, . . . a world into which, moreover, he would place himself as a member." ${ }^{2}$ But how do you determine whether or not you can will a given maxim as a law of nature? Since the will is practical reason, and since everyone must arrive at the same conclusions in matters of duty, it cannot be the case that what you are able to will is a matter of personal taste, or relative to your individual desires. Rather, the question of what you can will is a question of what you can will without contradiction.

According to Kant, willing universalized maxims may give rise to contradictions in two ways: 
Some actions are of such a nature that their maxim cannot even be thought as a universal law of nature without contradiction, far from it being possible that one could will that it should be such. In others this internal impossibility is not found, though it is still impossible to will that their maxim should be raised to the universality of a law of nature, because such a will would contradict itself. We easily see that the former maxim conflicts with the stricter or narrower (imprescriptible) duty, the latter with broader (meritorious) duty.

(G 424/41-42)

The first sort of contradiction is usually called a contradiction in conception, and the second a contradiction in the will.

In this paper I am concerned with identifying the sense in which there is a "contradiction" in willing the universalization of an immoral maxim, and especially with the sense in which the universalization of such a maxim can be said to have a contradiction in it - that is, with the idea of a contradiction in conception. There are three different interpretations of the kind of contradiction Kant has (or ought to have) in mind found in the literature. ${ }^{3}$ They are:

i) The Logical Contradiction Interpretation. On this interpretation, there is something like a logical impossibility in the universalization of the maxim, or in the system of nature in which the maxim is a natural law: if the maxim were universalized, the action or policy that it proposes would be inconceivable.

ii) The Teleological Contradiction Interpretation. On this interpretation, it would be contradictory to will your maxim as a law for a system of nature teleologically conceived: either you are acting against some natural purpose, or your maxim could not 
be a teleological law. The maxim is inconsistent with a systematic harmony of purposes, or with the principle that any organ, instinct, or action-type has a natural purpose for which it must be the one best suited.

iii) The Practical Contradiction Interpretation. On this interpretation, the contradiction is that your maxim would be self-defeating if universalized: your action would become ineffectual for the achievement of your purpose if everyone (tried to) use it for that purpose. Since you propose to use that action for that purpose at the same time as you propose to universalize the maxim, you in effect will the thwarting of your own purpose.

In trying to determine which of these views is correct, it is important to remember that it is not just because of the contradiction in the universalized maxim that immoral action is irrational. Kant is not claiming that immoral conduct is contradictory - if he were, the moral law would be analytic rather than synthetic. In any event, a contradiction in the universalization of your maxim would not prove that there is a contradiction in your maxim, for these are different. The Formula of Universal Law is a test of the sufficiency of the reasons for action and choice which are embodied in our maxims. The idea the universalizability is a test for sufficiency ("what if everybody did that?") is a familiar one, and shows in an intuitive way why it is rational to attend to a universalizability requirement. But the claim that universalizability is a test for a reason sufficient to motivate a rational being cannot be fully defended at this stage of the argument, for the full defense requires the connection to autonomy. Kant's critical ethical project is to prove that perfect rationality includes conformity to the categorical imperative: but in the Foundations this project is not directly taken up until the Third Section. ${ }^{4}$ The Second Section, where the Formula of Universal Law appears, is devoted to showing us what the content of the categorical imperative will be if there is one. The 
question of contradictions arises not in the context of determining why you must conform your conduct to the categorical imperative, but of how you do so.

Yet in trying to come to an understanding of how the Formula of Universal Law is to be applied, we must not lose sight of this further goal. Any view of how the Formula of Universal Law is applied must presuppose some view of what rational willing is. The problem is most obviously pressing for the case of contradictions in the will, for it seems impossible to say what contradicts a rational will until we know what a rational will is, or what it necessarily contains. There is a contradiction in one's beliefs if one believes both $\mathrm{x}$ and not $-\mathrm{x}$, or things that imply both $\mathrm{x}$ and not $-\mathrm{x}$. There is a contradiction in one's will if one wills both $\mathrm{x}$ and not-x, or things that imply both $\mathrm{x}$ and not-x. But until one knows what things are involved in or implied by "willing $\mathrm{x}$ ", one will not know how to discover these contradictions. So in determining which maxims can be willed as universal law without contradiction, we will have to employ some notion of what rational willing is. Some of the interpretations of the contradiction in conception test also rely on particular views of what rational willing is. This is why we must keep in view Kant's eventual aim of showing that moral conduct is rational conduct. Whatever view of the nature of rational willing is used in determining how the formula is to be applied must also be used in determining why it is rational to act as the formula prescribes.

One constraint this places on interpretations of the test is this: it must not employ a notion of rational willing that already has moral content. An example will show what I mean. John Stuart Mill says of Kant:

But when he begins to deduce from this precept any of the actual duties of morality, he fails, almost grotesquely, to show that there would be any contradiction, any logical (not to say physical) impossibility, in the adoption by all rational beings of the most outrageously immoral rules of 
conduct. All he shows is that the consequences of their universal adoption would be such as no one would choose to incur. ${ }^{5}$

Mill thinks that Kant's view really amounts to an appeal to utility, to what we would now call rule-utilitarianism. A rule-utilitarian interpretation of the Formula of Universal Law gives, as Mill points out, no sense to Kant's use of the word "contradiction" in this context. Yet, we could give it sense by claiming that a rational being is by definition opposed to undesirable consequences, and therefore cannot, without contradiction, will the universalization of any maxim if that universalization would have undesirable consequences. But roughly this kind of connection between a rational will and a moral will is what Kant is trying to establish, and therefore to use such a definition in explaining the contradiction test would make the Kantian argument circular. For if we use this definition we are already presupposing a morality-laden conception of what it is to be rational: we are assuming the sort of connection between moral goodness and rationality that Kant is preparing to demonstrate. So although the contradiction tests by themselves do not show us why immoral action is irrational, the notion of rational willing which they presuppose must be one that can be used at the later stage of the argument. My question is which of the three "kinds" of contradiction we should expect to find in the universalized version of an immoral maxim, and my aim is to defend the third answer, that it is a practical contradiction. I should say from the outset that although there is one important piece of textual evidence for this answer, it is my view that no interpretation can be based on textual considerations alone. Language supporting all of them can be found in Kant's texts, and it seems possible that he was not aware of the differences among them. My defense of the practical contradiction interpretation will therefore be based primarily on philosophical considerations. For each interpretation I will ask (i) what kinds of cases it can handle, (ii) whether it can meet some standard 
objections, (iii) what sort of distinction between the contradiction in conception test and the contradiction in the will test is implied by it, and, most importantly, (iv) what presuppositions about rationality it makes and so what kind of case case it will allow Kant to make when he turns to the critical project of showing that morality is pure rationality.

\section{The Logical Contradiction Interpretation}

Some of Kant's defenders have tried to identify a contradiction of just the sort Mill denies can be found. Versions of a Logical Contradiction Interpretation have been defended by Dietrichson, Kemp, and Wood, ${ }^{6}$ among others. I suppose hardly any of this interpretation's proponents have held it in the pure form that Mill describes: what they have looked for is something very like a logical or physical impossibility. Part of the reason for this is that it is clear that nothing like a logical contradiction can be found for the contradiction in the will test, since we are explicitly told that maxims that fail that test are conceivable. But there is no question that much of Kant's language favors a Logical Contradiction Interpretation for the contradiction in conception test. He says that universalizations of immoral maxims destroy themselves (G 403/19), annihilate themselves ( $\mathrm{C}_{2}$ 27/27), are inconceivable or cannot be thought, and so on. The example that fits this view best is the false promising example. A man in financial difficulties considers "borrowing" money which he knows he can never repay. Kant explains how this fails the contradiction in conception test this way:

... the universality of a law which says that anyone who believes himself to be in need could promise what he pleased with the intention of not fulfilling it would make the promise itself and the end to be accomplished by it impossible; no one would believe what was promised to him 
but would only laugh at any such assertion as vain pretense. (G 422/40)

Proponents of the Logical Contradiction Interpretation tend to focus on the remark that the promise itself would be impossible, as this seems to be where a logical inconceivability would lie. Kant tells us that promises would be impossible if this maxim were universalized because no one would believe them. There are various ways to find a contradiction here. One could say that the contradiction is that we are trying to conceive a world in which the agent (and everyone with his purpose) is making a certain sort of false promise, but at the same time we are necessarily conceiving a world in which no one can be making this sort of promise, since you cannot make a promise (of this sort) to someone who will not accept it. Perhaps the clearest way to bring out a logical contradiction is to say that there would be no such thing as a promise (or anyway a repayment-promise) in the world of the universalized maxim. The practice of offering and accepting promises would have died out under stress of too many violations. Thus we are imagining a world in which the agent and everyone with his purpose is making a certain sort of promise, but also a world in which there is no such thing. And this is logically inconceivable. If universalizing a maxim makes the action proposed inconceivable, then, we can get a logical contradiction.

\section{$\underline{\text { A Problem about Violence }}$}

The difficulty in taking this line shows up in a problem that Dietrichson describes in "Kant's Criteria of Universalizability". He considers the case of a woman who has decided to consider the maxim "If I give birth to a baby weighing less than six pounds, I shall do everything in my power to kill it." ${ }^{7}$ Dietrichson points out that it is certainly possible to conceive the idea of every mother behaving according to this rule. In my view, Dietrichson's example is not a properly formulated maxim, since it does not 
mention the mother's reason for killing the child. The child's weighing less than six pounds is not by itself recognizable as a prima facie reason for killing it. Since the Formula of Universal Law is a test of the sufficiency of reasons, the maxim must include them. But this is not the problem brought out by Dietrichson's example. We can make the maxim one of killing children that tend to cry at night more than average, in order to get enough sleep. Either Dietrichson's maxim or mine could clearly be a universal law without a logical contradiction. There could in fact be worlds where these things happen. They could happen in our world.

Dietrichson's solution is to appeal to the second contradiction test, and to place this among the maxims whose universalizations cannot be willed although they can be conceived. But this will not work. Different ways of deriving duties lead to different kinds of duty, with different moral and legal consequences. In the Foundations, Kant associates the contradiction in the will test with wide, meritorious duties (G 424/42), and the duty not to kill a child is obviously not of that kind.

Since Kant's account of the division of duties changes it is worth noting that even the later views will not permit Dietrichson's solution. The examples in the Foundations are divided in the text into perfect duties to self, perfect duties to others, imperfect duties to self and imperfect duties to others. A footnote warns us, however, that Kant will make his own division of duties in the Metaphysics of Morals. (G 421/39) That work is divided into duties of justice and of virtue. Now it might seem tempting to simply identify duties of justice, narrow duties, perfect duties, and negative duties with one another and similarly to suppose that duties of virtue, wide duties, imperfect duties, and positive duties are the same. But this would be an oversimplification: Kant's categorizations are more intricate than that. ${ }^{8}$ For although the duties of virtue are said to be broad or wide duties, there are perfect and negative duties that appear in this category: the duty not to commit suicide (one of Kant's Foundations examples) being an 
important instance. The perfect duties of virtue are the duties not to abuse your own moral and physical person and duties of respect (as opposed to those of love) to others. (MM 464/130, § 41)

There is room for controversy about exactly what effect this complex categorization has on the derivation of the relevant duties. In the Foundations, Kant's view seems to be that all perfect duties, whether of virtue or of justice, are to be derived from the contradiction in conception test. At least, this is how he tries to derive the duty not to commit suicide. Later, I will explain why I think that the derivation of this duty given by Kant under the Formula of Universal Law in the Foundations does not work. My own opinion is that this is because the perfect duties of virtue require a more complex derivation than Kant gives them in the Foundations. Perfect duties of virtue spring from the fact that there are ends against which we must not act, and ends cannot be assigned to us by the contradiction in the conception test, although they can by the contradiction in the will test. Kant's own texts do not give us direct guidance here, for in spelling out the duties of virtue in the Metaphysics of Morals he for the most part uses the concepts and casuistical methods of the Formula of Humanity rather than that of Universal Law. But if one holds that all duties of virtue, perfect or imperfect, depend on obligatory ends, one might be tempted to use the contradiction in the will test, which now can identify some perfect duties, for cases like Dietrichson's.

But this move could not solve the problem because even if this is a way to derive some perfect duties they are still only duties of virtue if they are arrived at in this way. Like the imperfect duties of virtue that assign ends we are to promote, they are externally unenforceable because the law cannot make us hold an end. (MM 379-385/3643) Imperfect duties of virtue are wide duties because the law does not prescribe exactly what and how much you must do to promote the obligatory ends. Perfect duties of virtue are wide for the somewhat different reason that acting for the sake of these ends is 
something we must work towards - we cannot, in our "phenomenal" lives, just decide to act for the sake of these ends. (MM 392/51 and § 22, 446/110-111) You can decide to treat someone with outward respect, but you cannot just decide to treat them so out of real respect. The attitudes involved are ones that you must cultivate, a sort of internal labor that ethics assigns to us, and how much and what you can do may depend on the circumstances of your life and perhaps the temperamental obstacles you have to overcome. But the murder of a child does not merely show the mother's failure to value it as an end in itself (although it does do that). This means only that the mother lacks virtues that she ought to have. The murder is also an injustice, a violation of right, and the duty not to commit murder is - as duties of virtue are not - rightfully enforceable. (MM 218-221/17-20 and 383-384/40-41) This puts it into the category of duties of justice, which are enforceable. We need the contradiction in conception test to identify this kind of immorality. ${ }^{9}$

\section{$\underline{\text { Natural and Conventional Actions }}$}

The problem that is demonstrated by Dietrichson's example springs from the fact that the action contemplated is one of natural violence. In the promising case we were able to generate a logical contradiction because the practice of promising was, under stress of universal violation, ushered off the scene. There would no longer be such a thing as promising. No such analysis is available here, because killing cannot be ushered off the scene by the way it is employed. The reason is obvious. Promising is, in the sense developed by Rawls in "Two Concepts of Rules"10, a practice. Both the possibility and the efficacy of actions performed within a convention such as promising - such as making, accepting, and keeping promises - depend on the existence, by conventional establishment, of the practice. The practice is comprised of certain rules, and its existence (where it is not embodied in an institution with sanctions) consists in the 
general acknowledgement and following of those rules. Now it is perhaps difficult to say exactly under what conditions a practice exists. We know that practices can exist if their rules are violated sometimes, for they do. But they cannot exist if their rules are universally violated. One may generate the contradiction by saying that when this happens the practice has new rules and becomes a different practice, but this is somewhat obscure. The clearer thing to say is this: a practice has a standard purpose, and if its rules are universally violated it ceases to be efficacious for this purpose, and so ceases to exist. People find some other way to achieve it, and the practice simply goes out of business. This is what happens in Kant's false promising example. Repayment promises, because they are never accepted, become nonexistent. People either make no loans or find another way to ensure repayment. For this reason, all actions which could not intelligibly exist or would not be efficacious without the existence of practices, and yet violate the rules of those practices, are easily handled by both the Logical and the Practical Interpretations of the contradiction test. Willing universal violation creates an inconsistency by making the action-type that it universalizes a non-existent one, and ipso facto, ineffectual.

But in Dietrichson's case there is no practice. The action is killing, and no amount or kind of use of the action of killing is going to make it impossible. And this is because the existence of this kind of action and its efficacy depend only on the laws of nature, not on any conventional practice. For shorthand, I am going to call actions like promising "conventional actions" and actions like killing "natural actions." The Logical Contradiction Interpretation works well for immoral conventional actions, but it is not very clear how it can handle immoral natural actions. When an action's possibility depends only on the laws of nature it cannot become inconceivable through universal practice. 


\section{Two Hegelian Objections}

In my view, it is the difficulty about natural actions which is most damaging to the Logical Contradiction Interpretation. Before I turn to the other views, however, I should mention some objections that are usually taken to be its most serious problem. I will call these the Hegelian objections, since they were originally put forward by Hegel and

promulgated by Bradley and others. ${ }^{11}$ One of the Hegelian objections is that universal law test is empty. I will borrow the formulation used by H.B. Acton, discussing Kant's Critique of Practical Reason example of a man who is considering not returning a deposit (C2 27-28/26-27):

In an essay entitled On the Scientific Treatment of Natural Law (1803), Hegel says that all Kant's argument shows is that a system without deposits is contradicted by a system with deposits, but not that there is any contradiction in a system without deposits. Kant makes there seem to be a contradiction in a system without deposits because he assumes that everyone would want there to be deposits, and this, says Hegel, shows that Kant was assuming the system of property and was arguing that if everyone kept what belongs to others then there would be no system of property. The interesting question, Hegel goes on, is just why there should be property, and about this Kant says nothing. ${ }^{12}$

This objection as it stands does not hold. On the Logical Contradiction Interpretation, the contradiction lies not in envisioning a society in which there are no deposits, but in envisioning a society in which the agent and others with his purpose are making use of the deposit system even though there is no such thing. The contradiction 
is generated when the agent tries to will his maxim and the universalization of his maxim at the same time, or tries to will it for a system of which he is to be a part. The nonexistence of the practice that results from universalization is contradicted by the existence of it presupposed in the individual maxim.

The other Hegelian objection pulls in the opposite direction: instead of showing the test to be empty, it shows it to be too strong. Bradley describes it this way:

'Steal property" is a contradiction, for it destroys property, and with it possibility of theft.

We have no need here to push further a metaphysical argument against this view, for it supplies us at once with a crushing instance against itself. The essence of morality was a similar contradiction. ... Morality is ... as inconsistent as theft. 'Succor the poor' both negates and presupposes (hence posits) poverty: as Blake comically says:

Pity would be no more,

If we did not make somebody poor.

If you are to love your enemies, you must never be without them; and yet you try to get rid of them. Is that consistent? In short, every duty which presupposes something to be negated is no duty; it is an immoral rule, because self-contradictory. ${ }^{13}$

It is true that we cannot imagine a world in which people give to the poor and there are no poor. Since there is no one to give to, it is an impossible state of affairs. But the advocate of Logical Contradiction Interpretation can handle the objection. He can say that Bradley has misstated the maxim. The maxim is to succor those who need it, and 
this maxim can be consistently held (and in a degenerate sense acted on) in a world where no one needs help. The policy of succoring those who need it when no one does is not inconceivable. It merely gives one nothing to do.

\section{The Teleological Contradiction Interpretation}

According to the Teleological Contradiction Interpretation, when we test our maxim by the two contradiction tests under the Formula of the Law of Nature, we are to consider whether we could will the universalized maxim as a possible law in a teleologically organized system of nature. There are two versions of this view. The first, which I will call the simple view, is usually understood this way: the contradiction emerges when an action or instinct is used in a way that is inconsistent with its natural purpose, or is not used in a way that its natural purpose calls for. A problem with this view as I have just stated it is that it makes no real use of universalization. Yet, there is some textual support for this interpretation: Kant does not scruple to use teleological language, and there are five arguments in the published ethical writings in which Kant's reasoning is explicitly teleological. One is the argument about the function of practical reasoning in the first section of the Foundations. (G 395-396/11-12) That argument is certainly teleological - Kant indeed carefully sets forth its teleological basis - but it is not a derivation of duty. Of the other four, two appear in the Foundations, in connection with the first set of examples: in deriving the duty not to commit suicide (G 421422/39-40) and in deriving the duty of self-cultivation. (G 423/41) The other two are in the Metaphysics of Morals, where lying is said to violate the natural purpose of the power of communication (MM 429/91) and carnal self-defilement is denounced by appeal to the natural purpose of the sexual instincts. (MM 424-425/85-87) 
The second version of this view is that of H.J. Paton, spelled out in Chapter XV of The Categorical Imperative. ${ }^{14}$ Paton is the major proponent of the Teleological Contradiction Interpretation and Beck partly endorses Paton's view. Aune also believes that Kant relies on a teleological conception in applying the Law of Nature formulation. ${ }^{15}$ Paton thinks that it is clear that the laws of nature Kant had in mind were teleological rather than causal, and that the test is whether "a will which aimed at a systematic harmony of purposes in human nature could consistently will this particular maxim as a law of human nature." ${ }^{16}$ Paton's view differs from the simple view in that he thinks that a teleological system serves as the type of the moral law, rather than thinking that our actions must not contradict actual natural purposes. However, in his account of the examples he takes Kant's explicitly teleological language as evidence for his interpretation, although that language suits the simple view. ${ }^{17}$ The difference matters more than Paton seems to realize, for the presuppositions about rationality are different. On his own view the claim must be that a rational being as such values a systematic harmony of human purposes, whereas on the simple view we must claim that a rational being as such values natural purposes. In what follows I will consider both versions.

As I mentioned, the usual understanding of the Teleological view is that we find some way to assign natural purposes to various instincts and types of actions and then find the contradiction when universalized maxims involve uses of those instincts and actions that defeat the natural purpose or perhaps are merely deviant. The best evidence that Kant understood the contradiction test this way is the suicide example, ${ }^{18}$ and it can be made to fit this pattern.

In the first teleological argument in the Foundations, Kant offers this as a general principle of teleological judgment: "we assume as an axiom that no organ will be found for any purpose which is not the fittest and best adapted to that purpose." (G 395/11) 
We can use this regulative principle to assign natural purposes to action-types as well as to organs, instincts, and other organic arrangements. Kant uses it to establish that the attainment of happiness is not the natural purpose of practical reason - the argument being that since instinct would be a better guide to happiness than reason is, reason is not the fittest and best adapted thing for that purpose. So let us say that there is a teleological contradiction if we propose as a universal law that an certain organ, instinct, or action-type be used in a way that makes it less than the fittest and best device for achieving its natural purpose. For example, we will say that the "natural purpose" of promising is to establish trust and confidence and the cooperation which they make possible. False promising on a universal scale makes promising less than the best device for this natural purpose. The suicide case will work this way: self-love is for the natural purpose of self-preservation; in the system of nature that results from universalizing the maxim of committing suicide out of self-love, self-love would not be the instinct fittest and best adapted to the purpose of self-preservation. As Kant says, "One sees immediately a contradiction in a system of nature whose law would be to destroy life by the feeling whose special office is to impel the improvement of life." (G 422/40) So the standard set by the regulative principle of teleological judgment is not met.

An attraction of the Teleological Contradiction Interpretation is that it looks at first as if it is going to resolve the most difficult problem faced by the Logical Contradiction Interpretation, that of natural actions. Suicide, after all, is such an action. The reason that it is not hard to find a contradiction in willing the universal violation of a practice is that the practice has a standard purpose: universal violation causes people to find some other way to carry out this purpose, and that is why the practice is abandoned. The Teleological view promises to allow us to treat natural actions in a similar way, for it assigns these actions or the instincts that prompt them standard purposes like the ones 
practices have - namely natural purposes. Of course it is true that a natural action or instinct, unlike a practice, will survive its universal abuse. But this is not a problem for the Teleological Contradiction Interpretation, for the defender of this view can say that the action or instinct will not, if universally misused, be best fitted for its purpose. That, not the existence of the action-type or instinct, is his criterion for establishing the contradiction.

But there is a difficulty with this solution to the problem of natural actions and with the proposed reading of the suicide case generally. It is that the suicide himself is not supposed to be able to will the teleological system based on the universalization of his maxim. Now it may be said that the suicide certainly cannot will the teleological system resulting from the universalization of his maxim, since, qua teleological system, it has a contradiction in it (an instinct not best adapted to its purpose). But this is a curiously abstract way to make a case against suicide. The contradiction in the teleological system is, after all, that a mechanism designed for the protection of life is malfunctioning. But the suicide doesn't want the mechanism to function well in his own case, and he may be indifferent about other cases. So neither his own purpose nor anything else commits him to the purpose. So if Kant's point were that the suicide cannot will the teleological system in question because qua teleological system it has a contradiction in it, Kant would simply be committed to the view that a rational being as such wills a well-functioning teleological system, regardless of whether he wills the purposes that it serves. But then it is hard to see how the argument can go through. This instinct would be malfunctioning with regard to this purpose, but nothing prevents the suicide from willing that both the instinct and its purpose be scrapped. The problem is that of the first Hegelian objection: just in the same way that Hegel says that there is no contradiction in willing away deposits because the world does not require them, so the suicide will say that the world does not require a self-preservation instinct (or any 
other teleological device) to make people go on living unless one supposes that it is better that people go on living. But this is what a suicide undertakes not to suppose. And we cannot use the answer to that objection that we used before. In the false promising case we said, using the Logical Contradiction view, that the man who is unable to will the universalization of the maxim of false promising does envision promising going on. He is going to make a promise. But the suicide's intention does not require him either to will or to envision the well-functioning of the self-preservation instincts. $\mathrm{He}$ does not plan to use them, or care whether they exist.

This objection does not apply in the same way to Paton's view. On Paton's view, the order of nature is a typic for the systematic harmony of human purposes. He supposes that a rational agent is committed to this harmony. One might object that this has the same problem as the utilitarian view: it presupposes a morality-laden view of reason. But Paton can counter this objection. He cites as evidence Kant's argument in the Critique of Practical Reason that self-love cannot be the basis of morality because it does not produce a harmony of purposes. $\left(\right.$ C2 28/27-28) ${ }^{19}$ And he might also cite as evidence the Critique of Pure Reason view that a harmony of purposes is the highest formal unity of pure reason. ${ }^{20}$ These things may be taken to imply that Kant thinks that rationality commits us to a harmony of purposes. Of course, this conclusion does not necessarily imply that when we reason morally we reason from such a harmony - it might instead be that this is a harmony that morality teaches us how to achieve. However that may be, the idea that a rational being is committed to a harmony of purposes will only help us with the Formula of Universal Law if we can somehow establish that the proposed natural purpose of the action-type is one needed for the systematic harmony of all human purposes and therefore is one that the agent must will.

The problem shows up in Paton's analysis of the false promising case. He reads the Teleological Contradiction Interpretation into the promising case by suggesting that 
the purpose of promises is to produce trust and mutual confidence; false promises

destroy trust and therefore universalization makes the purpose of promising impossible. Paton comments:

What Kant says is true enough so far as it goes, but it does not offer a satisfactory basis for moral judgment unless we make the further assumption that the keeping of such promises and the mutual confidence thereby aroused are essential factors in the systematic harmony of human purposes. $^{21}$

That is, we have to presuppose that the teleological system needs promises. Again, we get a problem like that of the first Hegelian objection.

On either Paton's or the simple view, the teleological analysis requires a commitment to specific purposes: either purposes of nature (like the preservation of life in the suicide example) or purposes required for the systematic harmony of human purposes. The trouble with bringing in teleological considerations in order to assign these purposes to natural as well as conventional actions is that such purposes may have nothing to do with what the agent wants or ought rationally to want, or even with what any human being wants. Unless we can show that the agent is committed to the purpose, it is possible to say that the system can do without the teleological arrangement because it can do without the purpose.

The Practical Contradition Interpretation, which appeals to thwarting of the agent's own purpose in formulating the maxim in the first place, will solve this problem.

\section{The Practical Contradiction Interpretation}

According to the Practical Contradiction Interpretation ${ }^{22}$ of the contradiction in conception test, the contradiction that is involved in the universalization of an immoral 
maxim is that the agent would be unable to act on the maxim in a world in which it were universalized so as to achieve his own purpose - that is, the purpose that is specified in the maxim. Since he wills to act on his maxim, this means that his purpose will be frustrated. If this interpretation is correct, then it is essential that in testing maxims of actions the purpose always be included in the formulation of the maxim. It is what happens to the purpose that is the key to the contradiction.

The test is carried out by imagining, in effect, that the action you propose to perform in order to carry out your purpose is the standard procedure for carrying out that purpose. $^{23}$ What the test shows to be forbidden are just those actions whose efficacy in achieving their purposes depends upon their being exceptional. If the action no longer works as a way of achieving the purpose in question when it is universalized, then it is an action of this kind. Intuitively speaking, the test reveals unfairness, deception, and cheating. For instance, in the false promising case, the difficulty is that the man's end getting the money - cannot be achieved by his means - making a false promise - in the world of the universalized maxim. The efficacy of the false promise as a means of securing the money depends on the fact that not everyone uses promises this way. Promises are efficacious in securing loans only because they are believed, and they are believed only if they are normally true. Since promising is the means he proposes to use, his end would not be achieved at all, but frustrated. In willing the world of the universalized maxim and - as Kant says - at the same time - willing the maxim itself, the man wills the frustration of his own end. As Kant says, the man "would make the promise itself and the end to be accomplished by it impossible." (G 422/40) This way of looking at the test also shows us one sense in which violations of the universal law test imply that you are using others as mere means. If you do something that only works because most people do not do it, their actions are making your action work. In the false promising case, other people's honesty makes your deceit effective. 


\section{$\underline{\text { Practical Contradictions }}$}

Even proponents of this view, or versions of it, sometimes describe a practical

contradiction as being a contradiction in a weaker sense than a theoretical one. ${ }^{24}$ This is not correct. Kant's ethics is based on the idea that there is a specifically practical employment of reason, which is not the same as an application of theoretical reason. It includes a specifically practical sense of "contradiction". The argument that shows this seems to me to be an almost decisive one in favor of this interpretation.

After laying out the three kinds of imperatives, Kant tells us that hypothetical imperatives are analytic. This means, ordinarily, two things: the relation expressed is one of conceptual containment, and the opposite or denial is a flat contradiction. Intuitively, we can see why failing to conform your conduct to relevant hypothetical imperatives, and thus frustrating your own purposes, is contradictory. Someone who wills an end, knows that it will be brought about by a certain necessary and available means, has no extraneous reason not to use that means, and yet is utterly unmoved to take it, is irrational in a way that does seem to amount to contradiction. ${ }^{25}$ We might capture the sense that there is a contradiction here by saying that such a person is acting as if she both did and didn't will the end. But Kant can do better than that, for he also explains the containment relation that makes the hypothetical imperative analytic:

Whoever wills the end, so far as reason has decisive influence on his action, wills also the indispensably necessary means to it that lie in his power. This proposition, in what concerns the will, is analytical; for, in willing the object as my effect, my causality as an acting cause, i.e. the use of means, is already thought, and the 
imperative derives the concept of necessary actions to this end from the concept of willing this end. (G 417/34-35)

The argument is based on an idea that plays a central role in Kant's ethics generally, namely that willing is regarding yourself as a cause: that the will is, as Kant says in the opening argument of Section Three of the Foundations, "a causality of living beings insofar as they are rational". (G 446/64) It is because we must regard ourselves not only as a cause but as a free cause or a first cause that it turns out rationality requires autonomy, and this is the basis of moral obligation. In the argument above, Kant's point is this: Willing is regarding yourself as the cause of the end in question - as the one who will bring it about. This distinguishes willing from mere wanting or wishing or desiring. Conceiving yourself as a cause of the end is conceiving yourself as setting off a causal chain that will result in the production of the end. It is conceiving yourself as using the available causal connections. But the available causal connections are, by definition, "means". So, willing the end contains, or insofar as you are rational is already, willing the means. It is because this is a "containment" relation - in the logic of practical reason that acting against the hypothetical imperative is contradictory. This gives us a sense of practical contradiction - of contradiction in the will - which is different from but not weaker than "theoretical" contradiction.

Since this is the sort of contradiction implied by the analyticity of hypothetical imperatives, it is reasonable to think that this will be the sort of contradiction employed in the categorical imperative tests. On the Practical Contradiction Interpretation, such a contradiction in the universalization of an immoral maxim is exactly what the test shows. In the world of the universalized maxim, the hypothetical imperative from which the false promiser constructs his maxim is no longer true. It was "if you want some ready cash, you ought to make a false promise." But at the same time that he employs this hypothetical imperative in constructing his maxim, he wills its falsification, by willing a 
state of affairs (the world of the universalized maxim) in which it will be false. In that world, false promising is not a means to getting ready cash. Kant, therefore, not only has a specifically practical sense of "contradiction", but should be seen as employing it in his contradiction tests.

\section{The Hegelian Objections}

Like the Logical Contradiction Interpretation, the Practical Contradiction Interpretation enables us to answer the Hegelian objections, and it shows even more clearly why those objections miss the moral point of a universalization test. The first Hegelian objection is that the universalization test is empty. There is no contradiction in a system without such practices as deposits or promises. The proponent of the Logical Contradiction view replies that the contradiction is not merely in a system without these practices but in an agent engaging in these practices in a system without them. On the Practical Contradiction Interpretation the answer we shall give is still better. The person who tries to will the universalization of this maxim is not only thereby willing a situation in which practices like deposits and promises do not exist. He is also willing that they do exist, precisely because he is willing to use them to achieve his ends. The man who wills the universalization of the false promise, for example, is also willing to use a false promise to get the money. But he cannot rationally will to use a promise to achieve his end at the same time that he wills a situation in which promises will not be accepted, because if his promise is not accepted it is not a means to achieving his end. Thus the Practical Contradiction Interpretation's answer to this Hegelian objection is that Kant need not be assuming that everyone wants there to be deposits. The man in the example wants there to be a system of deposits, because he proposes to use that system as the means to his end. In a clear sense he is unfair. 
The second objection was that the test is too strong. You cannot universalize "succor the poor," since if everyone did this poverty would be eliminated and there would be no one to succor. The Practical Contradiction Interpretation answers this objection both readily and, in an obvious way, correctly. One's purpose in succoring the poor is to give them relief. The world of the universalized maxim only contradicts one's will if it thwarts one's purpose. A world without poverty does not contradict this purpose, but rather satisfies it another (better) way, and no contradiction arises. ${ }^{26}$

\section{Contradictions in Conception and in the Will}

Another advantage of this view is that it should enable us to employ the same sense of contradiction in interpreting the two contradiction tests, and yet still to distinguish between them. Consider what the other two interpretations say about this question. The Logical Contradiction Interpretation forces us to look for a different sort of contradiction altogether for the contradiction in the will test, since Kant is explicit about the fact that no logical inconceivability is involved there. The Logical Contradiction Interpretation seems initially to have the virtue that it involves no presuppositions about rationality that are not completely uncontroversial. The contradiction it identifies in universalizing immoral maxims is of a familiar kind. But this advantage is lost if we must use different presuppositions in order to understand the contradiction in the will test. Often, proponents of the Logical Contradiction Interpretation for contradictions in conception end up with something like a utilitarian or a teleological view about contradictions in the will. But the utilitarian reading has the same problem for the second test as it does for the first: it presupposes a morality-laden conception of rationality. The Teleological Contradiction Interpretation, on the other hand, does not seem to allow for a very well-defined distinction between the two tests. I suppose one may say that in the case of a contradiction in conception, some specific 
instinct or action is found not to be best adapted to its particular purpose; and in the case of a contradiction in the will, we lose some positive good needed for a teleological system, or for the systematic harmony of human purposes. But it is not really obvious that these are distinct. Recall that Paton could not find a contradiction in the false promising case without assuming that promises are needed for the harmony of human purposes. This problem tends to collapse the two tests.

Now consider the Practical Contradiction Interpretation. If a thwarted purpose is a practical contradiction, we must understand the contradiction in the will test this way: we must find some purpose or purposes which belong essentially to the will, and in the world where maxims that fail these tests are universal law, these essential purposes will be thwarted, because the means of achieving them will be unavailable. Examples of purposes that might be thought to be essential to the will are its general effectiveness in the pursuit of its ends, and its freedom to adopt and pursue new ends. The arguments for self-development and mutual aid will then be that without the development of human talents and powers and the resources of mutual cooperation, the will's effectiveness and freedom would be thwarted. This is of course just a sketch. Exactly which purposes are essential to the will and how they can be shown to be so is a topic in its own right, which I will not pursue further here. The point is that the Practical Contradiction Interpretation gives a better account of the relation between the two tests than either of the others. The difference between the two tests will not lie in the use of a different kind of contradiction, as it does in the Logical Contradiction Interpretation. And yet there will be a difference. The purpose thwarted in the case of a maxim that fails the contradiction in the conception test is the one in the maxim itself, and so the contradiction can be said to be in the universalized maxim. The purpose thwarted in the case of the contradiction in the will test is not one that is in the maxim, ${ }^{27}$ but one that is essential to the will. 


\section{The Problem of Natural Actions}

The Practical Contradiction Interpretation, like the Logical, works especially well with respect to wrong actions which are conventional. But the reason why it works is slightly different. On the Logical Contradiction Interpretation, the contradiction arises because the agent wills to engage in a conventional action, but he also wills a state of affairs in which that kind of action will no longer exist. On the Practical Contradiction Interpretation, the contradiction arises because the agent wills to engage in a conventional action, but he also wills a state of affairs in which that action will no longer work. When we are dealing with an action that falls under a practice, the two views are readily confused, because the reason the action no longer works is because it no longer exists. But on the Practical Contradiction Interpretation it is the failure of efficacy, not the non-existence, that really matters.

This gives rise to the possibility that with the Practical Contradiction Interpretation we will be able to derive at least some of our duties of omission with respect to natural actions. Natural actions are not going to cease to exist if used wrongly, but their efficacy for some purposes may depend on their exceptional use. A great deal depends here on what the purpose is taken to be and how it is described. One case that is borderline between natural and conventional is stealing. That might seem wholly conventional, since property is a practice, but it is difficult to imagine an economic system in which the means of production and action were not guaranteed to the use of particular persons at particular times. ${ }^{28}$ And any violation of these guaranteed assignments would be "stealing". Now if the purpose of stealing is to acquire something for your personal use or possession - to get something you want when you want it - and you imagine that anyone in your situation - anyone who wants something not assigned to him - steals it, as a standard procedure - then you see that under these conditions it is quite impossible to acquire something for your use or possession, to have it when you 
want it. The idea here is that what the thief really wants is to make something his property, to have some guarantee that he will have it when he wants it. His purpose is therefore thwarted if his maxim is universalized.

That case is borderline, but a similar analysis might apply to wholly natural acts. Here is a silly example. Suppose you are second in line for a job, and are considering murder as a way of dealing with your more successful rival. Can this be universalized? Killing is a natural act, not a conventional one. We cannot say that if this sort of action is abused the practice will die out, for that makes no sense whatever. Nor can we say that any amount or kind of use of killing will destroy its efficacy in achieving its purpose if we specify that purpose simply as that of getting someone dead. So here the test will only work if the purpose is specified differently. We must say that the purpose is that of securing a job, and we must emphasize the fact that if anyone else wants this job, or any job you hold, universalization makes you the victim. Now, it may seem that the purpose that is thwarted by universalization - that of staying alive - is not the same as the purpose in your maxim - that of securing the job. This would be bad. It is the fact that it is the purpose in the maxim that gets thwarted in the world of the universalized maxim that enables us to carry out the test without any extraneous information about the agent's desires and purposes. If it is some other, contingent, purpose that gets thwarted, then it looks as if the test (i) requires empirical information about what other purposes people have and (ii) functions idiosyncratically, giving different results to people with different desires. These are both conclusions the Kantian wants to avoid. We shall avoid them here by pointing out that this is not a case of an extraneous end being thwarted. Staying alive matters in this example because it is a necessary condition of having the job.

That might seem like a silly thing to say in this case, but it is an application of a point which is not in general silly at all. In Utilitarianism, Mill argues that justice is 
specifically concerned with a special object of human interest - that of security. Security it not merely one good thing among others, but to put it in Kantian language, a condition of the goodness of anything else:

... but security no human being can possibly do without;

on it we depend for all our immunity from evil, and for the whole value of all and every good, beyond the passing moment; since nothing but the gratification of the instant could be of any worth to us, if we could be deprived of anything the next instant by whoever was momentarily stronger than ourselves. ${ }^{29}$

The Kantian may avail himself of this insight. To want something is to want to be secure in the possession of it. The use of violent natural means for achieving ends cannot be universalized because that would leave us insecure in the possession of these goods, and without that security these goods are no good to us at all. So, if we include as part of the purpose that the agent wants to be secure in the possession of the end, we can get a practical contradiction in the universalization of violent methods. And in fact, Kant's argument in the Metaphysical Elements of Justice about why there must be proprietary rights is not very different from Mill's: it is that we need to be secure in the possession of certain sorts of goods in order to successfully make use of them.(MM 246ff/52ff.)

The method of dealing with natural acts which I have just suggested focuses on the question whether you could really achieve your purpose - with everything that purpose involves (i.e. security in its possession) in a world where your action was the universal method of achieving that purpose. Another way to approach this problem is to consider whether the social conditions that allow violence to work as a method of achieving this purpose would exist if it were the universal method. It is true that natural laws are all that is needed to make violent methods yield their natural effects, but more 
is needed to make them yield their social effects. For example, the simplest way of making the argument against cheating on an entrance examination is to point out that if everyone did this the entrance examination would cease to be used as a criterion for selection. Since a lot of incompetent people would get in, it would be found impracticable and some other method would be chosen. ("Everyone would laugh at entrance examinations as vain pretenses.") Placing people in jobs is like this: it is something for which there must be a method, and if one method were universally abused, another, not liable to that abuse, would be found. Now if murder to get a job were universally practiced, the best candidates would not get the jobs. So whatever it is about the old selection process that makes this possible would be changed. Perhaps no one would be told who the candidates were, or people would even keep it a secret what jobs they held. Again, the argument sounds silly in this case but is meant to bring out something that is not silly. Cheating could not be the first or standard procedure for getting into an educational program. It is essentially parasitic on the existence of another method. Violence, in many cases, also has this parasitic nature when it is a way of achieving a purpose in society.

The Practical Contradiction Interpretation can therefore handle some cases of natural actions. A harder kind of case would be something like killing for revenge, or out of hatred. In these cases it is not some enduring condition that the agent wants to achieve - he wants the immediate result - so the security consideration will not help us here. ${ }^{30}$ These grim kinds of cases are managed without difficulty when using the Formula of Humanity, but it will be difficult to find any contradiction of the sort needed here. And this problem applies to the suicide case as well. On the Practical Contradiction Interpretation we cannot get an analysis of that case, for the suicide's purpose, if it is release from his own misery, will not be thwarted by universal practice. There is an important parallel to this problem. Kant's theory is least helpful and least plausible when 
one is dealing with a case where other people around the agent have already introduced evil into the situation. His debate with Benjamin Constant about whether one may lie to the murderer whose victim is hidden in your house, and his insistence that there is never a right to revolution, are infamous examples of cases in which his view seems to forbid us to try to prevent or to set right the wrongs committed by others. I believe that there is a similar sort of difficulty in making out what Kant is to say about cases where something has gone wrong inside, where the problem is not the selfish pursuit of an ordinary purpose, but a diseased purpose. I do not say that Kant is unable to give us an account of these cases. But the kind of case around which the view is framed, and which it handles best, is the temptation to make oneself an exception: selfishness, meanness, advantagetaking, and disregard for the rights of others. It is this sort of thing, not violent crimes born of despair or illness, that serves as Kant's model of immoral conduct. I do not think we can fault him on this, for this and not the other is the sort of evil that most people are tempted by in their everyday lives.

\section{$\underline{\text { Conclusion }}$}

It is conceivable that Kant did not perceive the differences among these three readings, and that this is why language supporting all of them can be found in his texts. In a certain kind of case, the three readings are very close. Where the immoral action involves the abuse of a practice, the Logical Contradiction Interpretation says you cannot universalize because the practice will not exist and the action will be inconceivable; the Teleological Contradiction Interpretation says you cannot universalize because the practice will then not be best suited for what in a teleological system would be its natural purpose; and the Practical Contradiction Interpretation says you cannot universalize because if the practice disappears it will of course no longer be efficacious in producing your purpose. These three analyses are very close, and for this kind of case the 
differences are insignificant. It is only when we begin to consider the problems created by natural actions, the Hegelian objections, and the need to extend our analysis in the right way to the contradiction in the will test that differences emerge. In my view, the Practical Contradiction Interpretation deals with these problems better than the other two, although not always with complete success.

The best argument for it, however, is that it employs the sense of contradiction which Kant identifies in his analysis of the hypothetical imperative. Each interpretation must presuppose some notion of rationality in determining whether a rational being can will the universalization of a maxim at the same time as that maxim without contradiction. The Logical Contradiction view works with a notion of contradiction indistinguishable from that of theoretical rationality and this is a great advantage. But this advantage is lost when we turn to contradictions in the will, which then require another interpretation. The Teleological Contradiction view works with a rather rich notion of rationality as aiming at a harmony of purposes. I think on Kant's view pure reason does aim at a harmony of purposes, but that only morality tells us how that is to be achieved. We cannot reason morally from that idea. The Practical Contradiction view uses a specifically practical notion of rationality and of contradiction which springs from the notion of the will as a causality. This is not a morality-laden notion of rationality, for on Kant's view this notion is needed to explain instrumental rationality.

Yet the same notion will also be employed in explaining why the moral law applies to us. The Practical Contradiction Interpretation allows us to sketch an explanation, in terms of autonomy, of why the conformity to the Formula of Universal Law is a requirement of reason. Start with a parallel to theoretical reasoning: as a rational being, you may take the connection between two events to be a causal one. But this connection must always hold - must hold universally - if the cause you have identified is indeed sufficient to produce that effect. Only in this case is what you have 
identified a law. The rational will, regarding itself as a causality, models its conception of a law on a causal law. As a rational being you may take the connection between a purpose you hold and an action that would promote it to be a reason for you to perform the action. But this connection must be universalizable if the reason is sufficient. Only in this case have you identified a law. If universalization would destroy the connection between action and purpose, the purpose is not a sufficient reason for the action. This is how, on the Practical Contradiction Interpretation, the contradiction in conception test shows an immoral maxim to be unfit to be an objective practical law. As an autonomous rational being, you must act on your conception of a law. This is why autonomy requires conformity to the Formula of Universal Law. ${ }^{31}$ 
Notes

1 References to Kant's ethical works will be given in the text, using the abbreviations below. In each case, the first number represents the page in the relevant volume of the Prussian Academy of Sciences edition of Kant's works, and the second the page number in the translation listed.

G Foundations of the Metaphysics of Morals. translated by Lewis White Beck. Library of Liberal Arts, 1959.

$\mathrm{C}_{2}$ Critique of Practical Reason. translated by Lewis White Beck. Library of Liberal Arts, 1956.

MM The Metaphysics of Morals. for the Preface and General Introduction, and for the Metaphysical Principles of Virtue, I have used the translation by James Ellington in Immanuel Kant: Ethical Philosophy. Hackett, 1983. For the Metaphysical Elements of Justice, see the translation by John Ladd, Library of Liberal Arts, 1965.

2 Immanuel Kant, Religion Within the limits of Reason Alone, translated by Theodore M. Greene and Hoyt H. Hudson. Harper Torchbooks, 1960. p. 5. 
3 Of course, these are general categories and fitting everyone's views into them would involve distortion; there are many slight differences in interpretation. I think, however, that they represent the main kinds of reading, and will indicate how I am classifying some important commentators as I present the views.

4 See the last paragraph of Section Two, G 444-445/63-64; also the last full paragraph on G 420/38.

5 John Stuart Mill, Utilitarianism, in Mill: Utilitarianism with Critical Essays, edited by Samuel Gorovitz, Bobbs-Merrill Text and Commentary Series, p. 15.

6 See Paul Dietrichson, "Kant's Criteria of Universalizability" in Kant: Foundations of the Metaphysics of Morals: Text and Critical Essays, edited by Robert Paul Wolff. BobbsMerrill, 1969. This essay is based on Dietrichson's "When is a Maxim Fully Universalizable?" Kant-Studien, Band 55, 1964. For Kemp's views, see J. Kemp, "Kant's Examples of the Categorical Imperative" The Philosophical Quarterly, Vol. 8 No. 30, 1958, also reprinted in Kant: Foundations of the Metaphysics of Morals: Text and Critical Essays. I attribute this view to Allen Wood on the basis of his paper "Kant on False Promises" in Proceedings of the Third International Kant Conference, edited by Lewis White Beck. Dordrecht Holland: D. Reidel, 1972. 
7 Dietrichson, "Kant's Criteria of Universalizability" Kant: Foundations of the Metaphysics of Morals: Text and Critical Essays, p. 188.

8 For a good discussion of this issue, see Onora Nell (O'Neill), Acting on Principle, An Essay on Kantian Ethics. Columbia University Press, 1975. Although I do not agree with this work on every point, it will be obvious to anyone who knows the book that I owe a great deal to it.

9 Kant does not use the Formula of Universal Law to derive the duties of justice in the Metaphysics of Morals. Instead he uses the Universal Principle of Justice, which tells us that our actions should be consistent with universalizable external freedom. (MM 230231/35) But in the Foundations, Kant suggests that violations of right are wrong in the same way as false promising ( $\mathrm{G} 430 / 48$ ), and this suggests that they should be derivable from the contradiction in conception test. Futhermore, it is reasonable to think that if injustices are by definiton inconsistent with universalizable external freedom, their universalizations should display contradictions in conception if anything does.

10 John Rawls, "Two Concepts of Rules". Philosophical Review 64, 1955.

11 Obviously, this discussion is not intended as a complete treatment of Hegel's criticisms of Kant's ethical philosophy. I mean only to cover some objections that recur in the literature and are usually referred to Hegel.

12 H. B. Acton, Kant's Moral Philosophy, Macmillan, St. Martin's Press, 1970, pp. 24-25. 
${ }^{13}$ F. H. Bradley, "Duty for Duty's Sake", Essay IV in Ethical Studies. (1876) Oxford, 1970, p. 155.

14 H. J. Paton, The Categorical Imperative (1947). University of Pennsylvania Press, 1971, pp. 146-157.

15 See Lewis White Beck, A Commentary on Kant's Critique of Practical Reason, Chicago, 1960, pp. 159-163; and Bruce Aune, Kant's Theory of Morals, Princeton, 1979, pp. 59ff.

16 Paton, The Categorical Imperative, p. 151.

17 This emerges when Paton, in discussing one of Kant's direct uses of teleological language, says that in this case "... Kant is on stronger ground. Here his teleology is more explicit. .." See The Categorical Imperative, p. 155.

18 This is contrary to the view of Paton, who thinks this example is the best evidence that Kant intended the typic to be ordinary causal laws, and also that it is not a good example. See The Categorical Imperative, p. 148.

19 Paton, The Categorical Imperative, p. 140.

20 Immanuel Kant, Critique of Pure Reason (1781 and 1787), A 686-687; B 714-715. translated by Norman Kemp Smith, Macmillan, St. Martin's Press, 1965, p. 560. 
21 Paton, The Categorical Imperative, p. 153.

22 This view is supported by Marcus Singer in Generalization in Ethics and a version of it is supported in Onora Nell (O'Neill), Acting on Principle: An Essay on Kantian Ethics.

23 The test works most smoothly where the hypothetical reasoning behind the maxim to be tested is purely instrumental. The problem of universalizing maxims like that of becoming a doctor in order to make one's living (the objection being that not everyone could do this) arises becasue the reasoning is constitutive. Being a doctor is an instance of a profession with certain features which the agent wants. The more we can specify these features, the closer we will come to the testable reasons that should be embodied in the maxim.

24 See for instance Singer, Generalization in Ethics, p. 259. Although Nell's version of the test is like the Practical Contradiction Interpretation in that she emphasizes the impossibility of acting on the maxim in the world of the universalized maxim, she supposes that Kant appeals to the Law of Nature formulation because applying the notions of self-defeat or self-frustration is not as clear as applying that of contradiction. See Acting on Principle, p. 63. Although she notes that Kant thinks that hypothetical imperatives are analytic, she thinks this is in a loose sense. (p. 70n)

25 Perhaps you will be tempted to say that this case does not occur. There would always be some extraneous reason for such a person not to take the means. This temptation is one to be resisted. Kant thinks that we are imperfectly rational: and one thing this means is that we will not always have reasons for being uninfluenced by reasons. It may 
be that there is always a cause of irrationality. Perhaps someone does not take the means to an end because she is depressed. This can be forced into the mold of a reason ("I feel so tired it would not be worth it to me right now"), and the agent herself will feel inclined to treat it that way. But it may not be the best way to describe what is really going on to say she has a reason not to take the means. If we think she would be better off taking the means even though she feels lethargic, we will find it better to say the depression is a cause of irrationality rather than that it changes the structure of the available reasons.

26 See the discussion in Singer, Generalization in Ethics,(1961) Atheneum, 1971, pp. $279-292$.

27 In Kant's first set of examples of the contradiction in the will test in the Foundations, there is no purpose given in the maxim. But even if we assigned purposes to the agents who adopt these maxims the point will hold. The man who does not develop his talents and powers presumably has the purpose of taking his ease. But the purpose that is thwarted is the development of his rational nature.

28 I do not mean that there has to be property in the thick Lockean sense of complete control of an object and absolute right to do anything with it. I only mean that there could not be a society in which persons did not have rights of use with respect to objects for certain durations - say the way you "own" the furniture in your office. Barbara Herman has pointed out to me that a system without something like promises may be just as hard to imagine, in which case those too will be a borderline case. 
29

Mill, Utilitarianism, in Mill: Utilitarianism, Text and Critical Essays, p. 50.

${ }^{30}$ Here is something we cannot do. We cannot get something like the security condition by saying that the vengeful killer wants to kill and get away with it - so, he wants not to be killed in turn himself, so he cannot universalize his vengeful maxim. We cannot say this because we don't know it. The security argument works only if we can say that security in the possession of a good or the continuance of a situation is really a condition of achieving that good or situation at all. It must not be a separate end. But wanting to get away with it is a separate end; getting away with it is not a condition of getting revenge. For notice that if we tried to make this our argument a vengeful killer would be morally all right if he did not mind paying the price.

31 I would like to thank Barbara Herman for comments which have enabled me to make this paper much clearer. 